\title{
Persistence with IDegLira in Patients in Clinical Practice: A Nationwide Observational Study in Sweden
}

\author{
Björn Eliasson (D) · Jan Ekelund - Mervete Miftaraj · Mattis Flyvholm Ranthe \\ Ann-Charlotte Mårdby · João Diogo Da Rocha Fernandes • \\ Ann-Marie Svensson
}

Received: April 16, 2020 / Published online: July 3, 2020

(C) The Author(s) 2020

\section{ABSTRACT}

Aims: To explore persistence with insulin degludec/liraglutide (IDegLira) treatment, clinical characteristics and concomitant medications in a large population of patients in clinical practice.

Digital Features To view digital features for this article go to https://doi.org/10.6084/m9.figshare.12514286.

Electronic supplementary material The online version of this article (https://doi.org/10.1007/s13300020-00872-4) contains supplementary material, which is available to authorized users.

B. Eliasson $(\varangle) \cdot$ A.-M. Svensson

Department of Molecular and Clinical Medicine, University of Gothenburg, Gothenburg, Sweden e-mail: bjorn.eliasson@gu.se

B. Eliasson - A.-M. Svensson

Department of Medicine, Sahlgrenska University Hospital, Gothenburg, Sweden

J. Ekelund · M. Miftaraj

Centre of Registers Västra Götaland, Gothenburg, Sweden

M. F. Ranthe · J. D. Da Rocha Fernandes

Novo Nordisk A/S, Søborg, Denmark

A.-C. Mårdby

Medical Affairs, Novo Nordisk, Malmö, Sweden

A.-C. Mårdby

Institute of Medicine, University of Gothenburg,

Gothenburg, Sweden
Methods: This was an observational study in patients with type 2 diabetes $(n=2432)$ who initiated IDegLira between 26 May 2015 and 31 December 2017. Data were obtained from Swedish nationwide registers and linked on an individual level using unique Swedish personal identifiers. Dose calculations were made for patients with $\geq 180$ days between the first and last collections of IDegLira prescription. Changes in clinical parameters were evaluated as change from the last observation during 12 months prior to the initiation date until \pm 90 days from the last collection of IDegLira.

Results: Pre-index regimens (index date being the date of filling the first prescription of IDegLira) included: multiple daily insulin injections (45.1\%); insulin and glucagon-like peptide-1 receptor agonist (GLP-1 RA) (19.7\%); long-acting insulins (11.8\%); non-injectable therapy only (11.4\%); GLP-1 RA only (9.8\%); and no collection of diabetes medication during the 6-month pre-index period (2.3\%). The majority of patients (94 and 84\%) were persistent with IDegLira at 6 and 12 months, respectively. The most commonly used concomitant medication was metformin (69.4\%). Mean daily dose was 33 dose steps. Overall, there was a mean decrease in HbA1c (approx. $10 \mathrm{mmol} / \mathrm{mol} \mathrm{[1 \% ])} \mathrm{and} \mathrm{body} \mathrm{weight}$ $(-1.1 \mathrm{~kg})$. Improvements in HbA1c were observed regardless of pre-index treatment. 
Conclusion: After 12 months, $84 \%$ of patients were persistent on IDegLira, with improved glycaemic control and reductions in body weight.

Keywords: GLP-1 analogue; Insulin therapy; Liraglutide; Real-world; Type 2 diabetes

\section{Key Summary Points}

Why carry out this study?

This observational study, based on data from Swedish national healthcare registries, was designed to build on the current real-world evidence base of IDegLira by exploring its use by a large cohort of adults with type 2 diabetes for up to 12 months.

The aim of the study was to characterise the use of IDegLira in clinical practice, and examine persistency with IDegLira treatment and change in glycaemic control and body weight.

\section{What was learned from the study?}

The majority of patients were persistent with IDegLira at 6 and 12 months after treatment initiation (94 and 84\%, respectively).

Overall, in patients initiating IDegLira, reductions in glycated haemoglobin (10.5 mmol/mol [1\%]) and body weight $(1.1 \mathrm{~kg})$ were observed after 6 months.

The mean dose used in this real-world population was 33 dose steps.

\section{INTRODUCTION}

In type 2 diabetes (T2D), optimal glucose and risk factor control can help reduce the longterm risk of microvascular and macrovascular complications [1]. Persistence (duration of time from initiation to discontinuation of medication) and adherence (extent to which a patient acts in accordance with the prescribed dosing regimen) to medication are key factors in optimising long-term glycaemic control [2]. However, non-persistence with injectable diabetes medications is particularly common in people with T2D [3], often due to the complexity of the therapeutic regimen [4].

IDegLira, a fixed-ratio combination of the basal insulin, insulin degludec (degludec) and the glucagon-like peptide-1 receptor agonist (GLP-1 RA), liraglutide, is used as a once-daily subcutaneous injection for the treatment of T2D [5]. Across the IDegLira clinical trial programme, mean end-of-treatment glycated haemoglobin (HbA1c) with IDegLira was $<53.0 \mathrm{mmol} / \mathrm{mol}(7.0 \%)$, with a mean end-oftrial daily dose of IDegLira ranging from 28 to 45 dose steps [6-14]. Overall, IDegLira resulted in improved glycaemic control compared with the use of its components alone [7], with a better weight profile, low rates of hypoglycaemia compared with insulin regimens $[10,12-14]$ and lower levels of gastrointestinal side effects when compared with GLP-1 RA monotherapy $[6,8]$. Furthermore, the cardiovascular (CV) outcomes trials examining the monocomponents of IDegLira, DEVOTE [15] (degludec vs. insulin glargine) and LEADER [16] (liraglutide vs. placebo), demonstrated that treatment with degludec was associated with no increased risk in the incidence of CV events and provided a significantly lower rate of severe and nocturnal hypoglycaemia compared with glargine U100, and that treatment with liraglutide was associated with a lower risk of CV events.

Although vast amounts of data from randomised clinical trials are available, these trials were not designed for the study of distinct subpopulations and do not show how IDegLira performs in a real-world setting over a set period of time. Currently, there are two retrospective, single-arm studies that have contributed to the body of data on IDegLira from randomised clinical trials $[17,18]$. In both studies, after 6 months, HbA1c was reduced by $10-18.6 \mathrm{mmol} / \mathrm{mol}(0.9-1.7 \%)$ with IDegLira compared with baseline $[17,18]$, with one study showing a lower risk of hypoglycaemia [17] and no observed mean weight gain [17]. These 
studies, however, include a low number of patients, 611 [17] and 61 patients [18], and do not address treatment management factors or persistence and/or concomitant treatment with IDegLira.

The observational study reported here, based on data from Swedish national healthcare registries, was designed to build on the real-world evidence base of IDegLira by exploring its use in a large cohort of adults with T2D. The aims of the study were to characterise the use of IDegLira in clinical practice, describe doses used in the real world, examine persistency with IDegLira treatment and report antidiabetic medications used concomitantly with, and after discontinuing, IDegLira, as well as the changes in glycaemic control and body weight.

\section{METHODS}

\section{Data Sources and Study Population}

Data from patients who initiated treatment with IDegLira between 26 May 2015 and 31 December 2017 were analysed using data from several nationwide health registers in Sweden. Data from the different registries were linked on an individual level using unique personal identifiers [19].

The National Diabetes Register (NDR), the primary aim of which is to collect clinical information on patients with diabetes, is estimated to include $90 \%$ of all Swedish adult patients with T2D. For the present study, clinical characteristics were extracted from the NDR [20]. The national Prescribed Drug Register (PDR) contains data on filled prescriptions from all pharmacies and includes information on the specific drug, date of dispensing, formula, package size and dosage. Data from the Swedish National Patient Register were used to obtain information about comorbidities, using the codes of the International Classification of Diseases, tenth revision (Electronic Supplementary Material [ESM] Appendix 1). Individualised data on socioeconomic status, including education, employment status and income, were extracted from the longitudinal integration database for health insurance and labour market studies
(LISA) [19]. Patients were entered into the study at the date of filling the first prescription. The records linkage procedure was performed by the Swedish National Board of Health and Welfare, and the data were delivered anonymously to the researchers.

The study conformed with the Declaration of Helsinki of 1964, as revised in 2013, concerning human and animal rights. Before entry in the register, all patients gave consent to registration and thus approved that their data may be used for research. The Swedish Ethical Review Authority approved the study.

\section{Persistence and Dose}

Persistence with IDegLira at 6 months following treatment initiation was defined as the collection of IDegLira at a pharmacy (based on the PDR) at least one more time within 6 months after the date of filling the first prescription of IDegLira (index date) (ESM Fig. S1). Patients had to initiate treatment with IDegLira before 30 June 2017 to be included in the 6-month persistence analysis. Twelve-month persistence was defined as the collection of IDegLira at the pharmacy (based on the PDR) at least one more time within 6 months after the index date, and a least one more time between 6-12 months after treatment initiation (ESM Fig. S1). Patients had to initiate IDegLira treatment before 1 January 2017 to be included in the 12-month persistency analysis; consequently, there were fewer patients included in the calculation for 12-month persistence. A patient who did not fill their IDegLira prescription during the second half of 2017 (1 July 2017-31 December 2017) was considered to have discontinued IDegLira treatment.

One dose step of IDegLira contains $1 \mathrm{U}$ of degludec and $0.036 \mathrm{mg}$ of liraglutide, with the highest daily dose of IDegLira being 50 dose steps (50 U degludec/1.8 mg of liraglutide), which reflects the maximum approved liraglutide dose for treatment of T2D [12]. One prefilled pen of IDegLira contains $3 \mathrm{~mL}$, equivalent to $300 \mathrm{U}$ of degludec and $10.8 \mathrm{mg}$ of liraglutide, with each pack containing three pens.

The average daily dose of IDegLira was estimated for the following time periods: first 
180 days after treatment initiation; first 365 days after treatment initiation; months 6-12 after treatment initiation (days 185-365, which was to be calculated for patients who had a last collection at least 365 days after initiation); last 180 days before last IDegLira collection during the study period (for persistent and non-persistent patients) and the time during the study period (26 May 2015-31 December 2017) between the first and last collection of IDegLira. In order to obtain a reasonably stable average dose, we set the shortest time period for which the mean daily dose could be calculated to 180 days. The rationale for selecting 180 days was that it was a sufficient length of time based on the Swedish reimbursement system, which allows an individual to collect a prescribed medication for approximately 3 months, with the possibility to refill the prescription after two thirds of the collection time has passed. As this represents at least a 3-month use at the minimum recommended starting dose, 6-month persistence was analysed using a minimum of two prescriptions.This approach reduced the impact of frequent collections due to certain circumstances, such as travelling and vacations. Additionally, this time period avoided very high average doses that may occur with a time period shorter than 180 days.

The mean daily dose over periods of 180 days was calculated as a moving average, starting at the date of first collection of IDegLira and ending 180 days before the last collection. Patients had to have at least 180 days between the first and last collection of their prescription during the study period to be included in the calculations of dose.

Since the maximum dose of IDegLira is $\mathbf{5 0}$ dose steps, a patient was categorised as a highdose user if the average dose for a period was $\geq 47$ dose steps (and indicative that the patient may have reached the maximum dose).

\section{Clinical Parameters}

Changes in HbA1c, body weight and body mass index (BMI) from the last observation during the 12 months immediately preceding the index date until \pm 90 days from most recent collection of IDegLira were measured.

\section{Concomitant Medication}

For those patients who were persistent with IDegLira therapy for 6 months, data on glucoselowering medications used concomitantly between the first and last collection of IDegLira, or after discontinuation of IDegLira therapy, were also collected.

\section{Statistical Analysis}

All analyses were descriptive, and no testing of hypotheses was performed. For continuous variables, data were summarised using means and standard deviations. For categorical data, frequencies and percentages were reported. The number of patients varied for each characteristic due to data availability. Confidence limits for mean within-group changes were calculated using the $t$ distribution.

\section{RESULTS}

A total of 3165 patients who filled at least one prescription of IDegLira during the study period between 26 May 2015 and 31 December 2017 were identified. Overall, 165 of these patients were not found in the Swedish NDR and were therefore excluded from the analysis (Fig. 1).

Six-month persistence with IDegLira therapy was studied in 2432 patients, among whom $2281(94 \%)$ and $151(6 \%)$ patients were persistent and non-persistent, respectively (Fig. 1; Table 1). Twelve-month persistence with IDegLira theapy was studied in 1760 patients, among whom 1482 (84\%) and 278 (16\%) were persistent and non-persistent, respectively. Baseline characteristics of and the most common treatments used by the study cohort prior to the initiation of IDegLira therapy, as identified from the Swedish NDR $(n=3000)$, are shown in ESM Table S1.

To assess the intensification of treatment and dosing of patients using IDegLira, we focused on the 2281 patients who were persistent with 


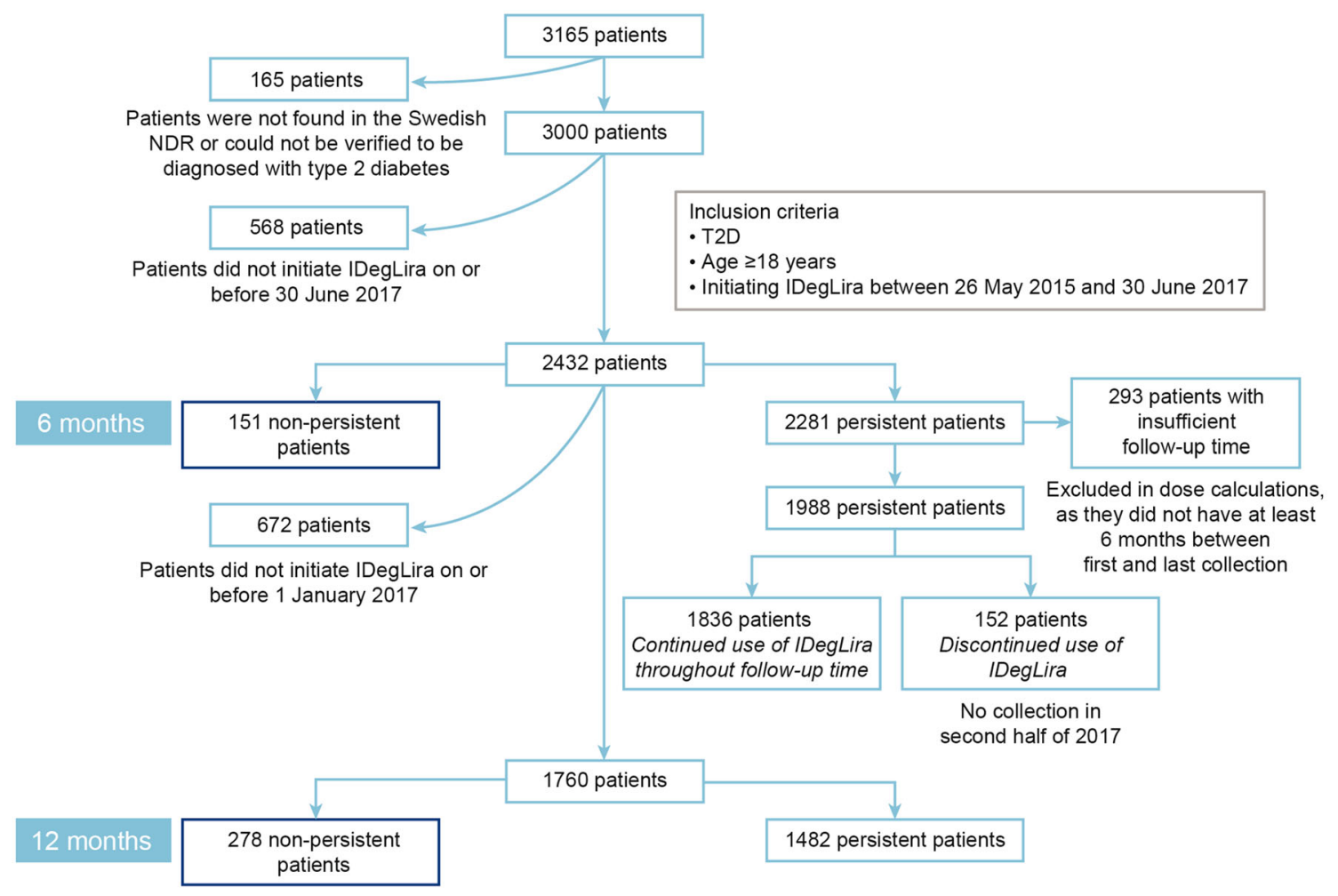

Fig. 1 Flow diagram of patient inclusion and exclusion. IDegLira Fixed-ratio combination of insulin degludec and liraglutide, $N D R$ National Diabetes Register, T2D type 2 diabetes

IDegLira at 6 months. The 293 patients who did not have at least 180 days between their first and last collection of IDegLira were excluded from the dose estimation analysis (Fig. 1); the remaining 1988 patients who showed 6-month persistence were included in the calculations of average dose (Fig. 1). In these 1988 patients, the most common medications used in the 6 months immediately preceding the index date included multiple daily insulin injections (45.1\%); combination treatment with insulin and GLP-1 RA (19.7\%); long-acting insulins (11.8\%); non-injectable therapy only $(11.4 \%)$; GLP-1RA only (9.8\%); and no collection of diabetes medication during the 6-month preindex period $(2.3 \%)$.

\section{Mean Daily Dose of IDegLira}

Of the 1988 patients with 6-month persistence and who were included in calculations of dose between the first and last collection of IDegLira, the mean daily dose was 33 dose steps (Table 2). A total of 1836 (92\%) patients continued using IDegLira throughout the follow-up period and 152 patients discontinued treatment with IDegLira. For the first and last 180 days, the mean IDegLira dose was 32 and 35 dose steps, respectively (Table 2 ). The mean IDegLira dose was 32-35 dose steps for all 180-day periods assessed.

In the subgroup analyses, patients who previously received non-injectable therapy and those who did not collect any diabetes medication in the 6 months prior to IDegLira initiation had the lowest mean doses of IDegLira compared with other prior treatment regimens (ESM Table S2).

Based on 6-month mean daily dose (moving average), $32 \%$ of all persistent patients were receiving $\geq 47$ dose steps at any given time (ESM Fig. S2). In total, 526 patients (26\%) were administered $\geq 50$ dose steps of IDegLira at any given time based on a 6-month mean daily dose (ESM Table S3). The proportions of patients 
Table 1 Baseline characteristics of patients included in the 6-month persistency analysis

\begin{tabular}{|c|c|c|c|}
\hline Variable & Total $(n=2432)$ & Persistent $(n=2281)$ & Non-persistent $(n=151)$ \\
\hline Age (years) & $61.3(11.8)$ & $61.3(11.6)$ & $60.2(14.3)$ \\
\hline \multicolumn{4}{|l|}{ Sex } \\
\hline Male & $1428(58.72 \%)$ & $1351(59.23 \%)$ & $77(50.99 \%)$ \\
\hline Female & $1004(41.28 \%)$ & $930(40.77 \%)$ & $74(49.01 \%)$ \\
\hline Diabetes duration (years) & $12.7(7.6)$ & $12.7(7.5)$ & $13.4(8.7)$ \\
\hline BMI $\left(\mathrm{kg} / \mathrm{m}^{2}\right)$ & $33.2(5.7)$ & $33.3(5.6)$ & $32.7(6.7)$ \\
\hline \multicolumn{4}{|l|}{ HbAlc } \\
\hline $\mathrm{mmol} / \mathrm{mol}$ & $74.0(16.8)$ & $73.8(16.6)$ & $75.6(18.2)$ \\
\hline$\%^{a}$ & $8.9(1.5)$ & $8.9(1.5)$ & $9.1(1.7)$ \\
\hline Systolic blood pressure (mmHg) & $134.5(15.6)$ & $134.5(15.5)$ & $135.2(17.3)$ \\
\hline Diastolic blood pressure $(\mathrm{mmHg})$ & $78.4(10.0)$ & $78.5(10.0)$ & $78.0(10.1)$ \\
\hline Total cholesterol $(\mathrm{mmol} / \mathrm{L})$ & $4.6(1.2)$ & $4.6(1.2)$ & $4.7(1.2)$ \\
\hline $\mathrm{LDL}(\mathrm{mmol} / \mathrm{L})$ & $2.6(1.0)$ & $2.5(1.0)$ & $2.6(1.0)$ \\
\hline $\mathrm{HDL}(\mathrm{mmol} / \mathrm{L})$ & $1.1(0.3)$ & $1.1(0.3)$ & $1.1(0.3)$ \\
\hline Triglycerides $(\mathrm{mmol} / \mathrm{L})$ & $2.3(1.7)$ & $2.3(1.6)$ & $2.7(2.7)$ \\
\hline Creatinine $(\mu \mathrm{mol} / \mathrm{L})$ & $77.5(25.8)$ & $77.5(25.7)$ & $76.8(27.0)$ \\
\hline $\mathrm{eGFR}\left(\mathrm{mL} / \mathrm{min} / 1.73 \mathrm{~m}^{2}\right)$ & $88.0(29.1)$ & $87.9(28.8)$ & $89.4(32.5)$ \\
\hline Microalbuminuria & $493(30.51 \%)$ & $460(30.34 \%)$ & $33(33.00 \%)$ \\
\hline Macroalbuminuria & $137(9.04 \%)$ & $126(8.85 \%)$ & $11(11.96 \%)$ \\
\hline Retinopathy & $711(41.85 \%)$ & $667(41.71 \%)$ & $44(44.00 \%)$ \\
\hline \multicolumn{4}{|l|}{ Physical activity } \\
\hline Never & $367(21.54 \%)$ & $332(20.80 \%)$ & $35(32.41 \%)$ \\
\hline$<1$ time/week & $293(17.19 \%)$ & $275(17.23 \%)$ & $18(16.67 \%)$ \\
\hline 1-2 times/week & $337(19.78 \%)$ & $327(20.49 \%)$ & $10(9.26 \%)$ \\
\hline 3-5 times/week & $354(20.77 \%)$ & $328(20.55 \%)$ & $26(24.07 \%)$ \\
\hline Daily & $353(20.72 \%)$ & $334(20.93 \%)$ & $19(17.59 \%)$ \\
\hline Smoking & $293(16.64 \%)$ & $272(16.46 \%)$ & $21(19.27 \%)$ \\
\hline \multicolumn{4}{|l|}{ Educational level } \\
\hline Primary education $\leq 9$ years & $688(28.63 \%)$ & $644(28.56 \%)$ & $44(29.73 \%)$ \\
\hline Secondary education $\leq 3$ years & $1244(51.77 \%)$ & $1167(51.75 \%)$ & $77(52.03 \%)$ \\
\hline Post-secondary education & $471(19.60 \%)$ & $444(19.69 \%)$ & $27(18.24 \%)$ \\
\hline \multicolumn{4}{|l|}{$\geq 3$ years } \\
\hline Income $2014(\times 100$ SEK $)$ & $2199.0(1959.3)$ & $2214.5(1986.5)$ & $1965.0(1474.9)$ \\
\hline
\end{tabular}


Table 1 continued

\begin{tabular}{llll}
\hline Variable & Total $(\boldsymbol{n}=\mathbf{2 4 3 2})$ & Persistent $(\boldsymbol{n}=\mathbf{2 2 8 1})$ & Non-persistent $(\boldsymbol{n}=\mathbf{1 5 1})$ \\
\hline Born in Sweden & $1905(78.33 \%)$ & $1800(78.91 \%)$ & $105(69.54 \%)$ \\
\hline
\end{tabular}

Data are presented as the mean with the standard deviation (SD) in parenthesis unless otherwise stated. The number of patients varies due to variations in data availability

$B M I$ Body mass index, eGFR estimated glomerular filtration rate, $H b A l c$ glycated haemoglobin, $H D L$ high-density lipoprotein, $L D L$ low-density lipoprotein, $N$ number of patients in cohort, NGSP National Glycohemoglobin Standardization Program, $O A D$ oral antidiabetic drug, SEK Swedish krona

${ }^{a}$ NGSP standard

Table 2 Mean daily dose of IDegLira in patients who were persistent at 6 months and thereafter continued or discontinued IDegLira treatment

\begin{tabular}{lcccccc}
\hline Study group and subgroups & $n$ & Mean & SD & Median & Q1 & Q3 \\
\hline Overall & & & & & & \\
Continued IDegLira & & & & & & \\
Mean daily dose (dose steps) during days 0-180 & 1836 & 31.8 & 13.5 & 30.1 & 21.7 & 40.6 \\
Mean daily dose (dose steps) between first and last withdrawal & 1836 & 33.5 & 13.4 & 32.7 & 23.1 & 43.3 \\
Mean daily dose (dose steps) during last 180 days & 1836 & 35.1 & 15.5 & 34.2 & 22.9 & 45.9 \\
Discontinued IDegLira & & & & & & \\
Mean daily dose (dose steps) during days 0-180 & 152 & 31.6 & 13.2 & 31.8 & 21.8 & 41.5 \\
Mean daily dose (dose steps) between first and last withdrawal & 152 & 32.6 & 13.0 & 33.3 & 21.4 & 43.0 \\
Mean daily dose (dose steps) during last 180 days & 152 & 33.9 & 14.6 & 34.0 & 22.0 & 45.3 \\
\hline
\end{tabular}

IDegLira Fixed-ratio combination of insulin degludec and liraglutide, Q1 lower quartile, $Q 3$ upper quartile

crossing over this 47 dose-step threshold according to prior treatment regimen were: $28.2 \%$ of those on long-acting insulin analogues; $24.7 \%$ of those on GLP-1 RAs; $51.7 \%$ of those on a free combination of insulin and GLP-1 RAs; $32.2 \%$ of those on multiple daily insulin injections; $14.5 \%$ of those on non-injectable therapy; and $11.1 \%$ who did not collect any diabetes medication during the 6-month pre-index period. The data show that the majority of patients who exceeded the maximum dose of IDegLira were previously receiving a free combination of insulin and GLP-1 RA therapy (ESM Table S3).

\section{Clinical Outcomes}

The mean changes in HbA1c, weight and BMI from pre-index (last observation during the 12 months prior to index date) to \pm 90 days from the last collection of IDegLira (approximately 465 days after initiation of IDegLira therapy) are given in ESM Table S4. In patients who continued the use of IDegLira, there was a mean decrease in HbA1c $(-10.5 \mathrm{mmol} / \mathrm{mol}$ 
(a)

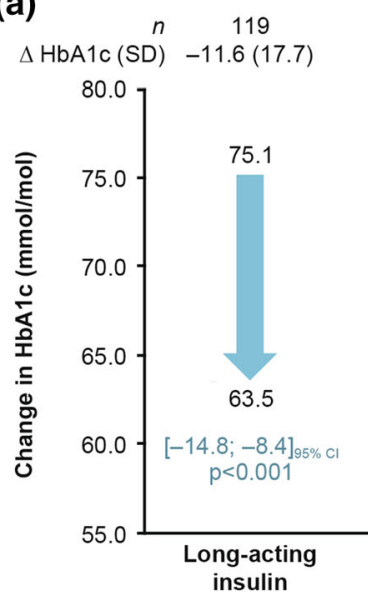

104

194

$-10.2(15.6)$

$-6.1(15.6)$

460

107

19

$-9.2(15.5)$

$-14.9(18.0)$

$-16.6(22.6)$
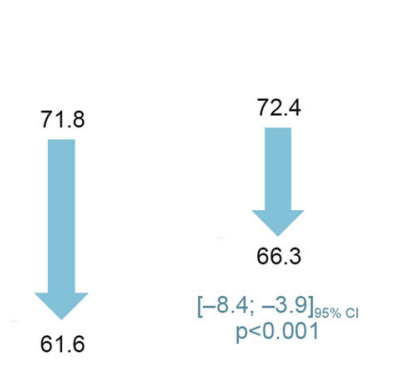

$[-13.2 ;-7.1]_{95 \% \mathrm{Cl}}$

$p<0.001$

p<0.001

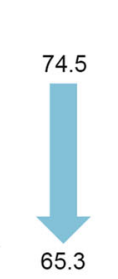

(b)

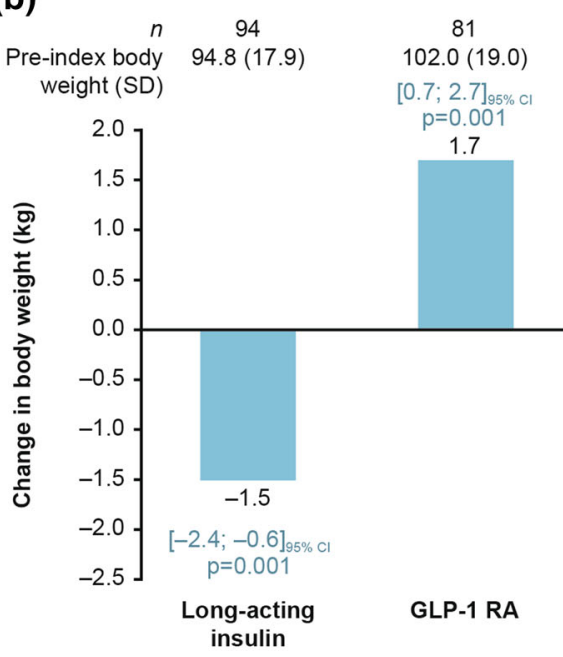

157

$99.1(18.8)$

345

$10.6 ;-7.8]_{95 \% \mathrm{Cl}}$
$\mathrm{p}<0.001$

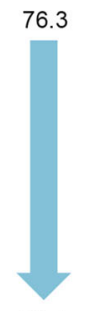

61.4

$[-18.3 ;-11.4]_{95 \% \mathrm{Cl}}$ $p<0.001$

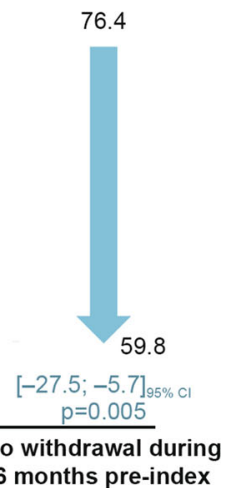

No withdrawal during
6 months pre-index

(c)

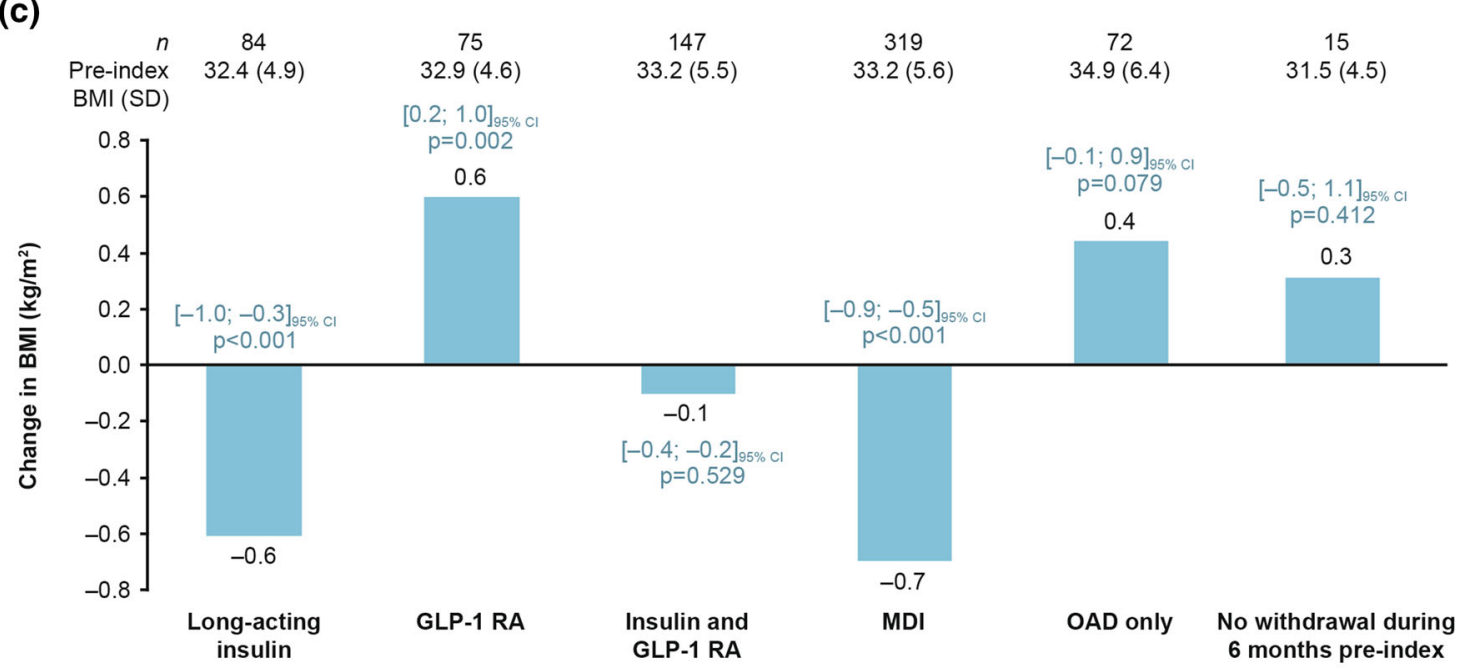


4Fig. 2 Observed mean changes in glycated haemoglobin (a) body weight (b) and BMI (c) from pre-index to \pm 90 days from the last collection of IDegLira during treatment period according to pre-index treatment. Data are shown as the mean (SD) unless otherwise stated. Confidence intervals (square brackets) and $p$ values are based on a within-group comparison. BMI Body mass index, GLP-1 RA glucagon-like peptide-1 receptor agonist, $H b A 1 c$ glycated haemoglobin, $M D I$ multiple daily injections, $O A D$ oral antidiabetic drug, $S D$ standard deviation

$[-1.0 \%]), \quad$ weight $(-1.1 \mathrm{~kg})$ and BMI $\left(-0.36 \mathrm{~kg} / \mathrm{m}^{2}\right)$.

Regardless of type of treatment during the pre-index period, improvements in $\mathrm{HbA} 1 \mathrm{c}$ were observed for all patients from pre-index (last observation during 12 months prior to index date) to \pm 90 days from the last collection of IDegLira (approximately 465 days) (Fig. 2a). In general, patients who did not collect any diabetes medication during the 6-month pre-index period achieved the greatest decrease in HbA1c $(-16.6 \mathrm{mmol} / \mathrm{mol}[-1.5 \%])$, and patients who were treated with a free combination of insulin and GLP-1 RA during the 6-month pre-index period achieved the smallest decrease in HbA1c $(-6.1 \mathrm{mmol} / \mathrm{mol}[-0.6 \%])$.

In patients who discontinued IDegLira use, mean HbA1c decreased by $-1.7 \mathrm{mmol} / \mathrm{mol}$ $(-0.2 \%)$, mean weight increased by $1.4 \mathrm{~kg}$ and mean BMI increased by $0.57 \mathrm{~kg} / \mathrm{m}^{2} 6$ months after initiation of IDegLira therapy.

Mean change in body weight and BMI varied slightly across all pre-index treatment regimens (Fig. 2b, c). Body weight increased in patients on GLP-1 RA (1.7 kg) or non-injectable therapy $(1.0 \mathrm{~kg})$ during the pre-index period; in contrast, a reduction in body weight was observed in patients on insulin regimens during the preindex period (Fig. 2b).

\section{Concomitant Medications and Medications Used After IDegLira Treatment was Discontinued}

The medications used concomitantly with IDegLira between the first and last collection of medications in patients with 6-month persistence $(n=1988)$ and the medications used during the 6 months after the last collection in patients who discontinued IDegLira use $(n=152)$ are shown in Table 3.

Overall, in patients with 6-month persistence, the most commonly used concomitant medication was metformin (69.4\%). Insulins were used by $29.6 \%$ of patients, the majority of whom were using fast-acting insulin analogues. In patients discontinuing treatment with IDegLira, during the 6 months following their last collection of IDegLira, the majority of patients collected insulins (67.1\%). Long-acting insulin analogues were collected by almost half of the patients who discontinued IDegLira (48.0\%), fast-acting insulin analogues were collected by $34.2 \%$ of patients and approximately $20 \%$ of patients collected GLP-1 RAs or sodium-glucose co-transporter-2 inhibitors.

\section{DISCUSSION}

This is a large, descriptive study investigating the use of IDegLira in patients with T2D in routine clinical practice, using high-quality nationwide Swedish data on disease and prescribed medications. The vast majority of patients (94 and 84\%) were persistent with IDegLira at 6 and 12 months, respectively. Regardless of the pre-index treatment regimen, an overall improvement in clinical outcomes in terms of mean decrease in HbA1c $(-10.5 \mathrm{mmol} / \mathrm{mol} \quad[-1.0 \%])$, body weight $(-1.1 \mathrm{~kg})$ and BMI $\left(-0.36 \mathrm{~kg} / \mathrm{m}^{2}\right)$ was observed, with an estimated mean dose of 33 dose steps.

Our study demonstrated a high rate of persistence with IDegLira compared with the persistence rate reported in studies of other injectable therapies. For example, a retrospective, observational study in the USA by Cooke et al. found that overall persistence with injectable antidiabetics administered once or twice daily (insulin glargine, insulin detemir, exenatide or isophane human insulin) during 1 year was $28.7 \%$ among patients with T2D who were insulin-naïve [3]. A French retrospective cohort study found that nearly $25 \%$ of patients with T2D, all of whom had not previously been 
treated with injectables, discontinued insulin [22]. However, as the current population was not insulin-naïve, a direct comparison cannot be made. In a retrospective database study by Wang et al. during a 1-year follow-up, 54.5\% of patients who had previously been treated with oral antidiabetic drugs (OADs) and/or GLP-1 RAs were persistent with insulin glargine [23]. The reasons for the persistency found in our study may be convenience, the low rates of hypoglycaemia observed in previous studies with IDegLira (not investigated in this study due to the dataset not containing accurate information on this item) or that the population in the current study was not restricted to patients naïve to injectable treatment $[7,10,12]$.

Importantly, the reported average IDegLira dose in our analysis, reflective of clinical practice, was generally lower than that used in published randomised clinical trials [6-10, 12, 14, 24]. In our study, the mean daily dose of IDegLira was approximately 33 dose steps, which is equivalent to approximately $1.2 \mathrm{mg}$ liraglutide [25]. This dose of $1.2 \mathrm{mg}$ liraglutide, however, is clinically relevant and reflects a dose often used in clinical practice [25]. In previous trials, patients who were uncontrolled on OADs only had a mean IDegLira dose ranging from 28 to 41 dose steps at the end of treatment $[6,9,13,14,24]$. The mean daily dose of 33 dose steps in the patients included our study could suggest a less aggressive approach to titration in clinical practice than in randomised clinical trials; based on the 6-month mean daily dose, approximately $26 \%$ of patients (526 patients) had a mean daily dose of IDegLira of $\geq 50$ dose steps at any given time.

In the current study, the majority of patients exceeding the maximum dose of IDegLira were previously receiving the free combination of insulin and GLP-1 RA therapy. In two treat-totarget clinical trials in patients uncontrolled on insulin glargine $100 \mathrm{U} / \mathrm{mL}[10,12]$, after treatment with IDegLira was initiated, the mean doses of IDegLira were 40 and 41 dose steps, respectively, and 34 and $40 \%$ of patients, respectively, were receiving the maximum doses of IDegLira after 26 weeks of treatment. The reasons for the excess in dosage require investigation in further studies. The observed HbA1c reduction and the proportion of patients on the maximum IDegLira dose suggest that, overall, IDegLira was titrated adequately in this sample, although strategies for achieving adequate titration may be of value.

The most common concomitant medication in patients with 6-month persistence was metformin, which indicates that initiating IDegLira in patients who had received metformin may be an option to consider as a way to improve the management of T2D in Sweden. Interestingly, fast-acting insulin analogues were prescribed concomitantly with IDegLira, and these were commonly initiated after treatment with IDegLira was discontinued, suggesting that some patients selected for IDegLira may have been in need of prandial control.

In our study, the mean decrease in HbA1c was approximately $10 \mathrm{mmol} / \mathrm{mol}(1.0 \%)$. Overall, mean HbA1c decreased by $10.5 \mathrm{mmol} / \mathrm{mol}$ $(1.0 \%)$ in patients who continued IDegLira use. In patients who discontinued IDegLira, mean HbA1c decreased by $1.7 \mathrm{mmol} / \mathrm{mol}(0.2 \%)$. The reasons for discontinuing IDegLira are unknown, but could be due to a lack of efficacy. The results in our study indicate that patients discontinued (in the pharmaceutical drug register) their treatment due to a lack of improvement in clinical outcomes. The present data support that, in patients previously treated with a free combination of insulin and GLP-1 RA therapy, a mean improvement in glycaemic control of $-6.1 \mathrm{mmol} / \mathrm{mol}(-0.6 \%)$ and mean weight loss of $-0.5 \mathrm{~kg}$ can be observed after Sweden initiation of IDegLira.

The reductions in HbA1c and body weight reported here are consistent with the results from the European observational (EXTRA) study [17]. In the EXTRA study, patients were previously treated with a wide variety of therapies, including insulin, GLP-1 RA, a free combination of insulin with GLP-1 RA, multiple daily injections or non-injectable therapy, similar to the current study [17]. In both studies, across all pre-index regimens, HbA1c was lowered, with greater decreases observed in patients previously treated with non-injectable therapies. Also in the EXTRA study, patients previously treated with multiple daily injections had the 
Table 3 Concomitant medication in persistent patients and medication following discontinuation of IDegLira, both at 6 months

\begin{tabular}{|c|c|c|}
\hline Drug type & $\begin{array}{l}\text { Concomitant medication between } \\
\text { first and last collection in all 6-month } \\
\text { persistent patients }(n=1988)\end{array}$ & $\begin{array}{l}\text { Concomitant medication after last } \\
\text { collection for patients who discontinued } \\
\text { IDegLira within } 6 \text { months }(n=152)\end{array}$ \\
\hline \multicolumn{3}{|l|}{ No. of OADs } \\
\hline 0 & $460(23.14 \%)$ & $61(40.13 \%)$ \\
\hline 1 & $1174(59.05 \%)$ & $62(40.79 \%)$ \\
\hline 2 & $314(15.79 \%)$ & $21(13.82 \%)$ \\
\hline 3 & $38(1.91 \%)$ & $7(4.61 \%)$ \\
\hline 4 & $2(0.10 \%)$ & - \\
\hline 5 & - & $1(0.66 \%)$ \\
\hline Biguanides & $1379(69.37 \%)$ & $73(48.03 \%)$ \\
\hline Sulfonylureas & $121(6.09 \%)$ & $9(5.92 \%)$ \\
\hline Alpha-glucosidase inhibitors & $11(0.55 \%)$ & - \\
\hline Thiazolidinediones & $29(1.46 \%)$ & $4(2.63 \%)$ \\
\hline DPP-4 inhibitors & $85(4.28 \%)$ & $14(9.21 \%)$ \\
\hline SGLT-2 inhibitors & $299(15.04 \%)$ & $30(19.74 \%)$ \\
\hline Oral drugs, combinations & $55(2.77 \%)$ & $7(4.61 \%)$ \\
\hline Insulins only & $588(29.58 \%)$ & $102(67.11 \%)$ \\
\hline $\begin{array}{l}\text { Insulins and analogues for } \\
\text { injection, fast-acting }\end{array}$ & $416(20.93 \%)$ & $52(34.21 \%)$ \\
\hline $\begin{array}{l}\text { Insulins and analogues for } \\
\text { injection, intermediate-acting }\end{array}$ & $78(3.92 \%)$ & $20(13.16 \%)$ \\
\hline $\begin{array}{l}\text { Insulins and analogues for } \\
\text { injection, intermediate- or long- } \\
\text { acting, combined with fast- } \\
\text { acting }\end{array}$ & $37(1.86 \%)$ & $12(7.89 \%)$ \\
\hline $\begin{array}{l}\text { Insulins and analogues for } \\
\text { injection, long-acting }\end{array}$ & $168(8.45 \%)$ & $73(48.03 \%)$ \\
\hline GLP-1 RAs & $63(3.17 \%)$ & $31(20.39 \%)$ \\
\hline Other glucose-lowering drugs & $64(3.22 \%)$ & $1(0.66 \%)$ \\
\hline
\end{tabular}

Percentages show the proportions of patients on concomitant medication $D P P-4$ Dipeptidyl peptidase-4, GLP-1 RA glucagon-like peptide-1 receptor agonist, SGLT-2 sodium-glucose co-transporter-2

greatest mean weight loss across all baseline therapy groups [17]. The findings of reductions in $\mathrm{HbA1c}$ in all groups of patients irrespective of previous therapy, weight gain in patients 
previously treated with GLP-1 RAs and weight loss in patients previously treated with insulin are consistent with those found in randomised clinical trials $[7,8,10,12]$.

The strengths of this study include the unprecedented large cohort of patients using IDegLira in a healthcare (primary and specialist care) real-world setting, a long follow-up period, collection of information on concomitant medication and limited reporting and selection bias due to the use of nationwide registers. Furthermore, this study uses a holistic analysis of clinical use by factoring in baseline characteristics, discontinuation, persistence, dose and clinical outcomes. As there is currently limited real-world evidence on patient persistence with IDegLira, a novel approach for investigation is presented. The limitations of this study include the absence of control or comparator data; therefore, it is not known how clinical parameters would have differed if patients did not initiate IDegLira. Moreover, there are variations in data extractions, as not all patients had the same amount of data available. As doses were estimated based on the time between collection of IDegLira and pack sizes, we do not know whether a patient actually administered IDegLira or not. Although this assumes a level of persistence to the suggested dosing, this may not be what is actually occurring. However, this definition of dosing has previously been used in similar real-world studies [26]. Hypoglycaemia and gastrointestinal side effects data were not captured; therefore, this is a priority for future studies. Moreover, whether patients discontinued OADs or reduced their dose of OADs after initiating IDegLira remains to be explored. As this study was conducted in Sweden only, there may be a lack of diversity in this cohort of patients, and further studies will be required to examine real-world use and effects of IDegLira in other patient populations. However, the reported findings are consistent with the findings from real-world studies in Europe $[17,18]$.

\section{CONCLUSION}

This study is based on nationwide data from Sweden and included 2432 patients with T2D who were prescribed IDegLira. The majority of patients were persistent regarding their treatment with IDegLira, with 94 and $84 \%$ of patients persistent at 6 and 12 months, respectively. The mean dose used in this real-world population was approximately 33 dose steps. Overall, in patients initiating IDegLira, reductions in $\mathrm{HbA} 1 \mathrm{c}$ (approximately $10 \mathrm{mmol} / \mathrm{mol}$ [1\%]) and body weight (1.1 kg) were observed.

\section{ACKNOWLEDGEMENTS}

Funding. This study and Rapid Service fees were supported by Novo Nordisk.

Medical Writing, Editorial, and Other Assistance. The authors thank the investigators, research coordinators, and patients in the study. The authors also thank Sejal Varsani and Helen Marshall (Watermeadow Medical, an Ashfield Company, part of UDG Healthcare plc.) for providing medical writing and editorial support, funded by Novo Nordisk.

Authorship. All named authors meet the International Committee of Medical Journal Editors (ICMJE) criteria for authorship for this article, take responsibility for the integrity of the work as a whole, and have given their approval for this version to be published.

Prior Presentation. Parts of this study were presented as a poster presentation at the American Diabetes Association, 79th Scientific Sessions, June 7-11, 2019, San Francisco, CA, USA.

Disclosures. Bjorn Eliasson reports personal fees from Amgen, AstraZeneca, Boehringer Ingelheim, Eli Lilly, Merck Sharp \& Dohme, Mundipharma, Navamedic, NovoNordisk, RLS Global and Sanofi; and grants from Sanofi outside the submitted work. Jan Ekelund and Mervete Miftaraj declare no conflicts of interest. Ann-Marie Svensson declares no conflicts of interest. Ann-Charlotte Mårdby is an employee and shareholder of Novo Nordisk A/S. Mattis Flyvholm Ranthe is former employee and 
shareholder of Novo Nordisk A/S. João Diogo Da Rocha Fernandes is an employee of Novo Nordisk $\mathrm{A} / \mathrm{S}$.

Compliance with Ethics Guidelines. The study conformed with the Declaration of Helsinki of 1964, as revised in 2013, concerning human and animal rights. Before entry in the register, all patients gave consent to registration and thus approved that their data may be used for research. The Swedish Ethical Review Authority approved the study.

Data Availability. The datasets generated during and/or analysed during the current study are available from the corresponding author on reasonable request. No additional data available.

Open Access. This article is licensed under a Creative Commons Attribution-NonCommercial 4.0 International License, which permits any non-commercial use, sharing, adaptation, distribution and reproduction in any medium or format, as long as you give appropriate credit to the original author(s) and the source, provide a link to the Creative Commons licence, and indicate if changes were made. The images or other third party material in this article are included in the article's Creative Commons licence, unless indicated otherwise in a credit line to the material. If material is not included in the article's Creative Commons licence and your intended use is not permitted by statutory regulation or exceeds the permitted use, you will need to obtain permission directly from the copyright holder. To view a copy of this licence, visit http:// creativecommons.org/licenses/by-nc/4.0/.

\section{REFERENCES}

1. Rawshani A, Rawshani A, Franzen S, et al. Risk factors, mortality, and cardiovascular outcomes in patients with type 2 diabetes. $\mathrm{N}$ Engl J Med. 2018;379:633-44.

2. Donnelly LA, Morris AD, Evans JM, DARTS/MEMO collaboration. Adherence to insulin and its association with glycaemic control in patients with type 2 diabetes. Q J Med. 2007;100:345-50.

3. Cooke CE, Lee HY, Tong YP, Haines ST. Persistence with injectable antidiabetic agents in members with type 2 diabetes in a commercial managed care organization. Curr Med Res Opin. 2010;26:231-8.

4. Garcia-Perez LE, Alvarez M, Dilla T, Gil-Guillen V, Orozco-Beltran D. Adherence to therapies in patients with type 2 diabetes. Diabetes Ther. 2013;4:175-94.

5. Novo Nordisk. Xultophy® ${ }^{\circledR}$ summary of product characteristics. Bagsvaerd: Novo Nordisk; 2019. https://www.ema.europa.eu/en/documents/produ ct-information/xultophy-epar-product-information _en.pdf. Accessed 30 June 2020.

6. Gough SC, Bode B, Woo V, et al. Efficacy and safety of a fixed-ratio combination of insulin degludec and liraglutide (IDegLira) compared with its components given alone: results of a phase 3, open-label, randomised, 26-week, treat-to-target trial in insulin-naive patients with type 2 diabetes. Lancet Diabetes Endocrinol. 2014;2:885-93.

7. Buse JB, Vilsboll T, Thurman J, et al. Contribution of liraglutide in the fixed-ratio combination of insulin degludec and liraglutide (IDegLira). Diabetes Care. 2014;37:2926-33.

8. Linjawi S, Bode BW, Chaykin LB, et al. The efficacy of IDegLira (insulin degludec/liraglutide combination) in adults with type 2 diabetes inadequately controlled with a GLP-1 receptor agonist and oral therapy: DUAL III randomized clinical trial. Diabetes Ther. 2017;8:101-14.

9. Rodbard HW, Bode BW, Harris SB, et al. Safety and efficacy of insulin degludec/liraglutide (IDegLira) added to sulphonylurea alone or to sulphonylurea and metformin in insulin-naive people with type 2 diabetes: the DUAL IV trial. Diabet Med. 2017;34: 189-96.

10. Lingvay I, Pérez Manghi F, Garcia-Hernandez P, et al. Effect of insulin glargine up-titration vs insulin degludec/liraglutide on glycated hemoglobin levels in patients with uncontrolled type 2 diabetes: the DUAL $\mathrm{V}$ randomized clinical trial. JAMA. 2016;315:898-907.

11. Harris SB, Kocsis G, Prager R, et al. Safety and efficacy of insulin degludec/liraglutide (IDegLira) titrated once weekly (1 Wk) vs. twice weekly ( $2 \mathrm{Wk})$ in patients (pts) with T2D uncontrolled on oral antidiabetic drugs: DUAL VI study. Diabetes. 2016;65(Suppl 1):LB23 (Abstract 88-LB).

12. Billings LK, Doshi A, Gouet D, et al. Efficacy and safety of IDegLira versus basal-bolus insulin therapy 
in patients with type 2 diabetes uncontrolled on metformin and basal insulin: the DUAL VII randomized clinical trial. Diabetes Care. 2018;41: 1009-166.

13. Aroda VR, Gonzalez-Galvez G, Gron R, et al. Durability of insulin degludec plus liraglutide versus insulin glargine U100 as initial injectable therapy in type 2 diabetes (DUAL VIII): a multicentre, openlabel, phase $3 \mathrm{~b}$, randomised controlled trial. Lancet Diabetes Endocrinol. 2019;7:596-605.

14. Philis-Tsimikas A, Billings LK, Busch R, et al. Superior efficacy of insulin degludec/liraglutide versus insulin glargine U100 as add-on to sodium-glucose co-transporter-2 inhibitor therapy: a randomized clinical trial in patients with uncontrolled type 2 diabetes. Diabetes Obes Metab. 2019;21:1399-408.

15. Marso SP, McGuire DK, Zinman B, et al. Efficacy and safety of degludec versus glargine in type 2 diabetes. N Engl J Med. 2017;377:723-32.

16. Marso SP, Daniels GH, Brown-Frandsen K, et al. Liraglutide and cardiovascular outcomes in type 2 diabetes. N Engl J Med. 2016;375(4):311-22.

17. Price H, Bluher M, Prager R, Phan TM, Thorsted BL, Schultes B. Use and effectiveness of a fixed-ratio combination of insulin degludec/liraglutide (IDegLira) in a real-world population with type 2 diabetes: results from a European, multicentre, retrospective chart review study. Diabetes Obes Metab. 2018;20:954-62.

18. Sofra D. Glycemic control in a real-life setting in patients with type 2 diabetes treated with IDegLira at a single Swiss center. Diabetes Ther. 2017;8: 377-84.

19. Ludvigsson JF, Svedberg P, Olen O, Bruze G, Neovius $M$. The longitudinal integrated database for health insurance and labour market studies (LISA) and its use in medical research. Eur J Epidemiol. 2019;34:423-37.

20. Eliasson B, Gudbjornsdottir S. Diabetes care-improvement through measurement. Diabetes Res Clin Pract. 2014;106(Suppl 2):S291-S294294.

21. World Medical Association. World Medical Association Declaration of Helsinki: ethical principles for medical research involving human subjects. JAMA. 2013;310:2191-4.

22. Roussel R, Charbonnel B, Behar M, Gourmelen J, Emery C, Detournay B. Persistence with insulin therapy in patients with type 2 diabetes in France: an insurance claims study. Diabetes Ther. 2016;7: 537-49.

23. Wang L, Wei W, Miao R, Xie L, Baser O. Real-world outcomes of US employees with type 2 diabetes mellitus treated with insulin glargine or neutral protamine Hagedorn insulin: a comparative retrospective database study. BMJ Open. 2013;3: e002348.

24. Rodbard HW, Cariou B, Zinman B, et al. Comparison of insulin degludec with insulin glargine in insulin-naive subjects with Type 2 diabetes: a 2-year randomized, treat-to-target trial. Diabet Med. 2013;30:1298-304.

25. Lind $\mathrm{M}$, Matsson $\mathrm{PO}$, Linder $\mathrm{R}$, et al. Clinical effectiveness of liraglutide vs sitagliptin on glycemic control and body weight in patients with type 2 diabetes: a retrospective assessment in Sweden. Diabetes Ther. 2016;7:321-33.

26. Bonafede MMK, Kalsekar A, Pawaskar M, et al. A retrospective database analysis of insulin use patterns in insulin-naïve patients with type 2 diabetes initiating basal insulin or mixtures. Patient Prefer Adherence. 2010;4:147-56. 